\title{
PENGELOLAAN RESIKO ANGGARAN TERHADAP KINERJA ORGANISASI PADA PT. SUMITOMO INDONESIA
}

\author{
Endah Prawesti Ningrum ${ }^{1}$, Bintang Narpati ${ }^{2}$, Indra Lubis ${ }^{3}$ \\ Program Studi Akuntansi, Fakultas Ekonomi dan Bisnis, Universitas Bhayangkara Jakarta Raya, Bekasi ${ }^{1}$ \\ Program Studi Manajemen, Fakultas Ekonomi dan Bisnis, Universitas Bhayangkara Jakarta Raya, Bekasi ${ }^{2,3}$ \\ endah.prawesti@dsn.ubharajaya.ac.id ${ }^{1}$, b.narpati@gmail.com ${ }^{2}$, indra.lubis@dsn.ubharajaya.ac.id $^{3}$ \\ Penulis untuk Korespondensi/E-mail: endah.prawesti@dsn.ubharajaya.ac.id
}

\begin{abstract}
Abstrak
Tujuan penelitian ini adalah mengukur tingkat pengelolaan resiko anggaran terhadap kinerja organisasi pada PT. Sumitomo Indonesia. Metode yang digunakan adalah analisa deskriptif kuantitatif dengan metode purposive sebanyak 35 (tiga puluh lima) responden. Menggunakan teknik analisis regresi linier sederhana dengan hipotesis : Apakah ada pengaruh yang signifikan antara pengelolaan resiko anggaran terhadap kinerja organisasi pada PT. Sumitomo Indonesia. Hasil penelitian menunjukkan adanya pengaruh yang signifikan antara pengelolaan resiko anggaran terhadap kinerja organisasi sebesar 50\%. Apabila pengelolaan resiko anggran dijalankan sesuai prosedur dan tidak mengalami kebocoran ataupun adanya kejanggalan pada anggaran, maka akan meningkatkan kinerja organisasi secara signifikan. Organisasi tidak akan mengalami kerugian, namun peningkatan kinerja organisasi tidak hanya dipengaruhi oleh pengelolaan resiko anggaran saja, melainkan ada beberapa faktor lain yang mempengaruhinya, seperti pengawasan anggaran, pengelolaan laporan keuangan dan yang mendukung dalam peningkatan kinerja organisasi.
\end{abstract}

Kata Kunci : Pengelolaan Resiko Anggaran Dan Kinerja Organisasi.

\begin{abstract}
The purpose of this study is to measure the level of budget risk management on organizational performance at PT. Sumitomo Indonesia. The method used is quantitative descriptive analysis with a purposive method of 35 (three five-five) respondents. Using a simple linear regression analysis technique with a hypothesis: Is there a significant influence between budget risk management on organizational performance at PT. Sumitomo Indonesia The results of the study indicate that there is a significant influence between budget risk management and organizational performance by 50\%. If budget risk management is carried out according to procedures and does not experience leakage or any discrepancy in the budget, it will significantly improve organizational performance. The organization will not suffer losses, but the improvement in organizational performance is not only influenced by the management of budget risk, but there are several other factors that influence it, such as budgetary oversight, financial statement management and which support in improving organizational performance.
\end{abstract}

Keywords: Budget Risk Management and Organizational Performance.

\section{PENDAHULUAN}

Pada era globalisasi sekarang ini perkembangan dunia usaha yang semakin pesat mengakibatkan pada suatu kondisi persaingan yang semakin ketat antar perusahaan. Oleh karena itu, proses penetapan anggaran bervariasi di berbagai organisasi. Salah satu konsekuensi yang mungkin, "senjangan anggaran", didefinisikan sebagai "perkiraan biaya terlalu tinggi dan / atau perkiraan pendapatan terlalu rendah dalam proses penganggaran (CIMA, 2000). Kesenjangan anggaran disebut sebagai "perilaku disfungsional" 
dalam paradigm lama yang negative, Praktik akuntansi manajemen tradisional dianggap sebagai praktik akuntansi manajemen yang jangka pendek dalam fokus, dan berorientasi secara internal dan finansial (Pavlatos \& Paggios, 2011). Namun, aliran penelitian ini mengungkapkan temuan yang kontradiktif. tetapi dengan mengeksplorasi factor kontekstual dan factor pribadi lainnya, sehingga dapat mengadopsi pendekatan yang lebih fleksibel dalam menghadapi risiko yang mungkin terjadi yang disebut dengan strategi manajemen risiko anggaran.

Dalam menghadapi risiko yang mungkin terjadi pada perusahaan manufaktur, dan meningkatnya persaingan global, prevalensi praktik akuntan manajemen menggunakan kontrol anggaran tradisional masih dominan, tetapi tidak terkait oleh perubahan dan kinerja organisasi, sedangkan praktik akuntan manajemen yang menggunakan pendekatan kontemporer dapat merubah kinerja organisasi yang lebih kuat ke arah yang lebih baik. Penggunaan praktik akuntansi manajemen kontemporer dikaitkan dengan pengenalan inisiatif yang mempromosikan penambahan kegiatan bernilai tambah dan / atau penghapusan kegiatan yang tidak menambah nilai (Lanen \& Larcker, 2015). Bukti yang bertentangan dari studi sebelumnya memberikan motivasi bagi (Van Helden, G Jan \& Northcott, 2010) yang menemukan bahwa unit bisnis dengan strategi diferensiasi atau mereka yang lebih menguntungkan di masa lalu lebih fleksibel dan bahwa kontrol anggaran yang kurang kaku memungkinkan lebih banyak ruang untuk kendur penciptaan. (Stevens \& Stevens, 2002) menemukan bahwa masalah etika dan reputasi dapat memengaruhi penciptaan budgetary slack. (Leach \& Stemmerjohan, 2015) menyelidiki pengaruh sikap manajer terhadap proses anggaran dan penciptaan kelonggaran pada timbulnya kelonggaran anggaran, menggambarkan perilaku ini sebagai "taktik curang dan licik". Oleh karena itu, manajer berkontribusi terhadap kinerja melalui dampaknya terhadap stabilitas organisasi, dan dengan melindungi dan mengeksploitasi kejadian di lingkungan eksternal. Dalam serangkaian buku penting, (Malhotra, 2006) telah menempatkan manajemen publik dalam "logika pemerintahan" yang berjalan dari tuntutan publik di satu sisi untuk kepuasan pemangku kepentingan di sisi lain. Elemen-elemen manajemen dari kerangka ini termasuk struktur organisasi dan proses teknologi.

Perubahan kinerja organisasi dapat diidentifikasi melalui asset tidak berwujud seperti paten, pengetahuan dan inovasi sebagai sumber yang fundamental kekayaan dan kemajuan. Aset pengetahuan adalah aset tidak berwujud dari suatu negara, dan mereka memiliki implikasi yang signifikan untuk nilai nasional di masa depan, karena mereka mewakili sumber kompetensi dan kemampuan yang dianggap penting untuk pertumbuhan ekonomi nasional, pembangunan manusia, dan kualitas hidup (Malhotra, 2004). Akibatnya, negara-negara yang kaya akan aset tak berwujud lebih baik dalam hal kekayaan nasional daripada negara yang asetnya terbatas pada tanah, peralatan, dan tenaga kerja (Malhotra, 2004). Kinerja organisasi dipengaruhi oleh budaya. Budaya organisasi lebih banyak berada dalam praktik (terlihat dan sadar): cara orang memahami apa yang terjadi di lingkungan organisasi mereka. menggambarkan enam dimensi yang sama sekali berbeda yang ditemukan dalam (Hofstede, 2011) meneliti budaya organisasi. Ini memperingatkan terhadap kebingungan dengan perbedaan nilai di tingkat individu. Ini diakhiri dengan melihat ke depan dalam apa studi dimensi budaya nasional. Peneltian budaya banyak dilakukan pada kinerja perusahaan. Peneliti bermaksud meneliti hal tersebut Pengelolaan Risiko Anggaran Terhadap Kinerja Organisasi.

\section{TINJAUAN PUSTAKA}

\section{Kinerja Organisasi \\ Teori Kepemimpinan}

Potensi keberhasilan bisnis tergantung pada kinerja organisasinya, yang berarti kemampuannya untuk secara efektif menerapkan strategi untuk mencapai tujuan kelembagaan (Randeree, 2016). Beberapa variabel merupakan kinerja organisasi, seperti efektivitas model bisnis, efisiensi, dan hasil (Ryan, Spencer, Bernhard, \& Spencer, 2012) (Silva, 2009). Kinerja organisasi sebagian besar tergantung pada tingkat keterampilan yang dimiliki para pemimpinnya dalam hal menerapkan strategi. (Silva, 2009) menggambarkan esensi kepemimpinan sebagai hubungan kondisional yang ada antara manajer dan pengikutnya. Mengingat bahwa selalu ada rintangan untuk mencapai tujuan organisasi, penting bahwa teknik yang digunakan pemimpin cukup fleksibel untuk mengakomodasi perubahan. Kinerja organisasi juga tergantung pada karyawannya, yang merupakan bagian penting dari organisasi dan membentuk tim yang bekerja untuk mencapai tujuan organisasi. Konsep kepemimpinan sering dimasukkan dalam konteks tim virtual (Mukherjee, 2013). Tim virtual 
dibentuk oleh para pemimpin untuk memastikan pencapaian tujuan tertentu. Khususnya, penelitian menunjukkan bahwa tim virtual tidak dapat berhasil tanpa kepemimpinan yang efektif (Pech, 2003). Kompetensi kognitif dari kedua tim dan pemimpin juga dianggap penting untuk kinerja organisasi yang efektif.

Kinerja organisasi dan kompetensi kepemimpinan berkorelasi dengan kompetensi sosial, kognitif, dan kecerdasan emosional (EI) (Ryan et al., 2012). (Boyatzis, 2009) mengidentifikasi kecerdasan sosial sebagai kemampuan seorang pemimpin untuk fokus pada inovasi dan memotivasi itu di antara anggota timnya. Ini sering disebut sebagai kepemimpinan direktif dan sangat tergantung pada delegasi, di mana para pemimpin memahami bagaimana memberikan beberapa kekuatan kepemimpinan kepada anggota tim dan beri mereka ruang untuk mengeksplorasi ide-ide baru (Emrich, 1999). Di sisi lain, kompetensi kognitif menyoroti kemampuan kreatif dan kritis yang membantu meningkatkan pengambilan keputusan, pemecahan masalah, dan pembelajaran (Sun \& Hui, 2012). Seorang pemimpin yang mengembangkan visi dan strategi untuk mencapai visi tersebut harus secara efektif mengkomunikasikan elemen-elemen ini kepada karyawan. Teknik-teknik yang diterapkan para pemimpin termasuk tetapi tidak terbatas pada negosiasi, mempengaruhi, pemecahan masalah, pelatihan, dan memotivasi keberhasilan dalam kinerja organisasi, seorang pemimpin harus menggabungkan ketiga kompetensi untuk mempengaruhi kinerja karyawan. (Roberson \& Elaine, 2015) membangun korelasi positif antara kepemimpinan dan kinerja karyawan, yang keduanya berkontribusi pada efektivitas organisasi.

\section{Pengelolaan Resiko Anggaran}

Manajemen risiko muncul untuk pertama kalinya dalam terminologi CIMA hanya pada tahun 2005, didefinisikan sebagai: Proses memahami dan mengelola risiko yang entitas tak terhindarkan tunduk pada upaya untuk mencapai tujuan perusahaan (CIMA, 2005, hal. 53). Jika risiko bisnis dipandang sebagai risiko yang tidak dicapai oleh sasaran perusahaan, maka risiko anggaran dapat didefinisikan sebagai risiko bahwa kinerja akan menyimpang dari anggaran karena variasi perencanaan dan bukan operasi, yang mungkin timbul dari perubahan dalam lingkungan ekonomi. Ketidakpastian dalam proses penetapan anggaran dan proses kontrol telah dipelajari baik secara kuantitatif dengan cara yang lebih kualitatif (Collier et al., 2007), tetapi tidak ada hubungan yang secara eksplisit dibuat antara anggaran kendur dan risiko pengelolaan. Risiko adalah bidang pengendalian manajemen yang diidentifikasi oleh Berry et al. (2009) sebagai tema yang muncul, layak untuk penelitian lebih lanjut.

\section{METODOLOGI PENELITIAN}

Metode yang digunakan dalam penelitian ini adalah metode penelitian deskriptif kuantitaif dengan mengambil sample atau respon pada karyawan PT. Sumitomo Indonesia sebanyak 35 (tiga puluh lima) karyawan. Metode ini menggunakan dua variabel yaitu satu variabel bebas (X) yaitu pengelolaan resiko anggaran dan satu variabel terikat $(\mathrm{Y})$ yaitu kinerja organisasi. Data sekunder yang digunakan adalah literatur yang terkait dengan penelitian ini. Pengolahan data primer menggunakan SPSS 24.0 for windows dengan tingkat kepercayaan $95 \%$.

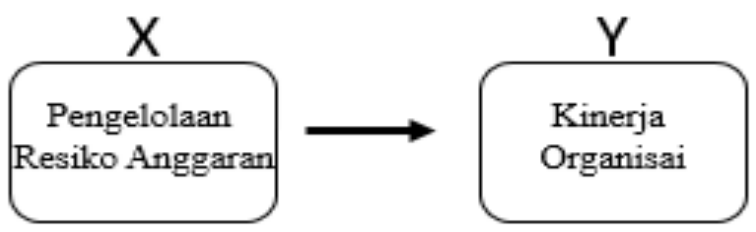

Gambar 1. Hubungan antara pengelolaan resiko anggaran terhadap kinerja organisasi

Pengujian hipotesis antara variabel $\mathrm{X}$ dan $\mathrm{Y}$ adalah apakah ada pengaruh secara signifikan Pengelolaan Resiko Angggaran terhadap Kinerja Organisasi ? dengan bentuk hipotesis sbb:

H0 : Tidak terdapat pengaruh yang signifikan antara pengelolaan resiko anggaran terhadap kinerja organisasi

$\mathrm{Ha}$ : Adanya pengaruh yang signifikan antara pengelolaan resiko anggaran terhadap kinerja organisasi

\section{HASIL DAN PEMBAHASAN}

\section{Hasil}

\section{Uji Kualitas Data}

1. Uji Validitas Instrument

Validitas instrumen memberikan nilai sebenarnya dari suatu permasalahan yang akan dikaji. Pengujian ini menganalisis tiap item dan mengkolerasikan skor yang dimiliki tiap butir dengan total skor yang merupakan jumlah skor tiap butir (Sugiyono, 2013). Kuesioner dikatakan valid apabila $r_{\text {-hitung }}>r_{\text {-tabel }}$. Pada Penelitian ini, $r$-tabel $=$ 
0,3338 dengan taraf signifikansi 5\% dan sample ( $\mathrm{N}$ $=97$ ).

Tabel 1. Uji Validitas Variabel X

Pengelolaan Resiko Anggaran

\begin{tabular}{|c|r|r|c|}
\hline Pertanyaan & r-hitung & r-Tabel 5\% (N=35) & Keterangan \\
\hline 1 & 0.8683 & 0.3338 & valid \\
\hline 2 & 0.8983 & 0.3338 & valid \\
\hline 3 & 0.8554 & 0.3338 & valid \\
\hline 4 & 0.8683 & 0.3338 & valid \\
\hline 5 & 0.8710 & 0.3338 & valid \\
\hline 6 & 1.0000 & 0.3338 & valid \\
\hline 7 & 0.8722 & 0.3338 & valid \\
\hline
\end{tabular}

Pada tabel 1 setelah dilakukan uji validitas atas semua butir - butir instrumen penelitian variabel bebas $(\mathrm{X})$, dihasilkan r-hitung memiliki nilai yang valid, begitu pula pada variabel $\mathrm{Y}$ memiliki nilai valid dengan $\mathrm{N}=7$ (tabel 2.).

Tabel 2. Uji Validitas Variabel Y

Kinerja Organisasi

\begin{tabular}{|c|r|r|c|}
\hline Pertanyaan & r-hitung & r-Tabel 5\% (N=35) & Keterangan \\
\hline 1 & 0.8877 & 0.3338 & valid \\
\hline 2 & 0.9003 & 0.3338 & valid \\
\hline 3 & 0.8895 & 0.3338 & valid \\
\hline 4 & 1.0000 & 0.3338 & valid \\
\hline 5 & 0.9416 & 0.3338 & valid \\
\hline 6 & 0.5690 & 0.3338 & valid \\
\hline 7 & 0.6520 & 0.3338 & valid \\
\hline
\end{tabular}

2. Uji Reliabilitas

Nilai sutau konstruk dikatakan reiable bila menunjukkan Cronbach's Alpha lebih besar dari 0,7 (sGhozali, 2011).

Tabel 3. Uji Reliabilitas Variabel X

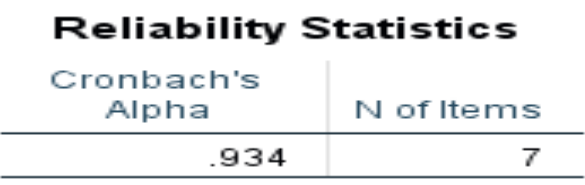

Tabel 3 menunjukkan nilai cronbach's alpha dari variabel bebas X sebesar 0,934 dan lebih besar dari 0,70 , sehingga variabel $X$ dikatakan reliable, sedangkan untuk variabel Y, cronbach's alpha dihasilkan nilai sebesar 0,946 atau lebih besar dari 0,70 , sehingga dapat dikatakan bahwa variabel $\mathrm{Y}$ adalah reliable.
Tabel 4. Uji Reliabilitas Variabel Y

\section{Reliability Statistics}

\begin{tabular}{r|r}
$\begin{array}{c}\text { Cronbach's } \\
\text { Alpha }\end{array}$ & N of Items \\
\hline .946 & 7 \\
\hline
\end{tabular}

\section{Uji Asumsi Klasik}

1. Uji Normalitas

Data dikatakan berdistribusi normal bila titik - titik menyebar mendekati sumbu diagonal grafik histogram dari residualnya (Ghozali, 2011). Pada penelitian ini titik - titik menyebar membentuk diagonal, sehingga variabel - variabel dikatakan normal. Pada uji Kolmogorov - Smirnov dihasilkan siginifikansi sebesar 0,200 atau lebih besar dari 0,05 .

Tabel 5. Uji Normalitas

One-Sample Kolmogorov-Smirnov Test

\begin{tabular}{llr} 
& & $\begin{array}{r}\text { Unstandardiz } \\
\text { ed Residual }\end{array}$ \\
\hline $\mathrm{N}$ & Mean & 35 \\
\hline Normal Parameters & a,b & .0000000 \\
\cline { 2 - 3 } & Std. Deviation & 5.08225080 \\
\hline Most Extreme Differences & Absolute & .103 \\
\cline { 2 - 3 } & Positive & .089 \\
\cline { 2 - 3 } & Negative & -.103 \\
\hline Test Statistic & & .103 \\
\hline Asymp. Sig. (2-tailed) & & $.200^{\mathrm{c}, \mathrm{d}}$ \\
\hline
\end{tabular}

a. Test distribution is Normal.

2. Uji Multikolinieritas

Uji Multikolonieritas adalah pengujian untuk mengetahui ada tidaknya kolerasi yang sgnifikan antar variabel-variabel independen dalam model regresi linier berganda. Dalam model regresi dapat digunakan VIF dan lawannya Tolerance untuk melihat ada tidaknya gejala multikolinieritas. Nilai cutoff Multikolonieritas adalah nilai Tolerance $>0,10$ dan nilai VIF $<10$ (Ghozali, 2011).

Dari output coefficients di bawah ini, nilai tolerance 0,100 atau lebih besar dari 1,000 sedangkan pada kolom VIF nilainya 1,000, maka dapat disimpulkan bahwa pada model regresi tidak ditemukan adanya masalah multikolinieritas. 
Tabel 6. Uji Multikolinieritas

Coefficients $^{\mathrm{a}}$

\begin{tabular}{llr|r|r|r} 
& & \multicolumn{2}{c}{ Unstandardized Coefficients } & \multicolumn{2}{c}{ Collinearity Statistics } \\
Model & \multicolumn{1}{c}{ B } & Std. Error & Tolerance & \multicolumn{1}{c}{ VF } \\
\hline 1 & (Constant) & 12.468 & 2.641 & & \\
\cline { 2 - 6 } & $\mathrm{X}$ & .585 & .102 & 1.000 & 1.000 \\
\hline
\end{tabular}

\section{a. DependentVariable: Y}

3. Uji Heterokedastisitas

Uji Heterokedastisitas digunakan untuk mengetahui adanya ketidaksamaan varian dan residual pada model regresi. Model regresi yang baik adalah yang Homoskedatisitas atau tidak terjadi heterokedastisitas (Ghozali, 2011). Pada uji heteroskedastisitas titik-titik mengumpul pada angka 0,1 dan -1 kemudian menyebar, sehingga tidak ditemukan gejala heteroskedastisitas.

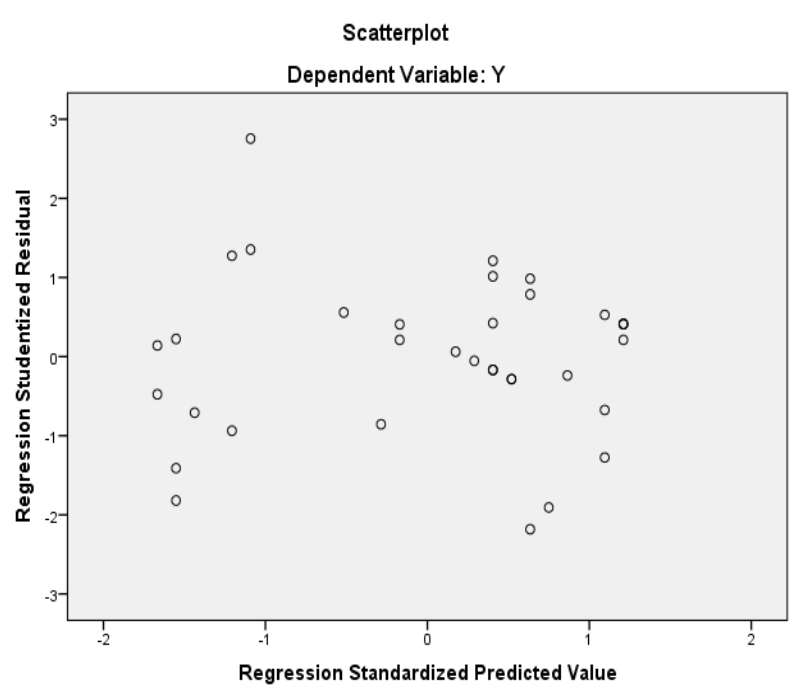

Gambar 2. Uji Heteroskedastisitas

\section{Analisis Linier Berganda}

Persamaan regresi dapat dirumuskan sebagai berikut (Sugiyono, 2013).

$$
\mathrm{Y}=12,468+0,585 \mathrm{X}
$$

\section{Pengujian Hipotesis}

1. Uji Signifikansi Parsial ( $\left.\mathrm{t}_{\text {-test }}\right)$

Uji parsial atau uji-t menggambarkan mengenai adanya pengaruh variabel yang satu dengan variabel yang lain dengan secara individu yang menjelaskan variabel terikat terhadap variabel bebas (Kuncoro, 2010).
Tabel 7. Hasil Uji Parsial Variabel Bebas

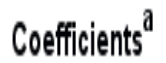

\begin{tabular}{|c|c|c|c|c|c|c|}
\hline \multirow[b]{2}{*}{ Mode } & & \multicolumn{2}{|c|}{ Unstandardized Coefficients } & \multirow{2}{*}{$\begin{array}{l}\text { Standardized } \\
\text { Coefficients } \\
\text { Beta }\end{array}$} & \multirow[b]{2}{*}{ t } & \multirow[b]{2}{*}{ Sig. } \\
\hline & & $B$ & Std. Error & & & \\
\hline \multirow[t]{2}{*}{1} & (Constant) & 12.468 & 2.641 & & 4.720 & .000 \\
\hline & $x$ & .585 & .102 & .707 & 5.749 & .000 \\
\hline
\end{tabular}

a. DependentVariable:Y

Nilai sig $<0.05$ yaitu 0,00 atau nilai t-hitung $5,749>$ t-tabel 2,0345 maka terdapat pengaruh variabel bebas Pengelolaan Resiko Anggaran (X) terhadap variabel terikat Kinerja Organisasi (Y).

Pada uji parsial di atas dapat disimpulkan bahwa adanya pengaruh yang signifikan antara variabel bebas $(\mathrm{X})$ terhadap variabel terikat $(\mathrm{Y})$.

2. Koefisien Determinasi $\left(\mathrm{R}^{2}\right)$

Koefisien determinasi $\left(\mathrm{R}^{2}\right)$ menerangkan variasi variabel terikat dalam suatu model (Kuncoro, 2010). Pada hasil koefisien determinasi $\left(\mathrm{R}^{2}\right)$ dihasilkan nilai 0,500 atau $50,0 \%$ yang berarti bahwa pengaruh variabel bebas $\mathrm{X}$ terhadap variabel terikat $\mathrm{Y}$ memiliki nilai sebesar 50,0\%, sedangkan sisanya $50,0 \%$ variabel yang tidak ada atau diteliti dalam penelitian ini.

Tabel 8. Koefisien Determinasi

$$
\text { Model Summary" }
$$

\begin{tabular}{rr|r|r|r|r} 
Model & R & R Square & $\begin{array}{l}\text { Adjusted R } \\
\text { Square }\end{array}$ & $\begin{array}{r}\text { Sttd Error of } \\
\text { the Estimate }\end{array}$ & \multicolumn{1}{c}{$\begin{array}{l}\text { Durbin- } \\
\text { Watson }\end{array}$} \\
\hline 1 & $.707^{\mathrm{a}}$ & .500 & .485 & 5.159 & 1.985 \\
\hline
\end{tabular}

a. Predictors: (Constant), $X$

b. Dependent Variable: $Y$

\section{Pembahasan}

Melalui beberapa uji statistika yang telah dilakukan terhadap dua variabel yaitu variabel bebas Pengelolaan Resiko Anggaran (X) dan variabel terikat yaitu Kinerja Organisasi (Y), secara hipotesis dapat ditarik kesimpulan bahwa terdapat pengaruh secara signifikan antara Pengelolaan Resiko Anggaran terhadap Kinerja Organisasi. Hal ini dapat dibuktikan dengan persamaan regresi linier yang membuktikan bahwa adanya hubungan linier antara Pengelolaan Resiko Anggaran terhadap Kinerja Organisasi. 


\section{KESIMPULAN}

Melalui uji-t dengan parsial dan uji-F secara simultan dengan variabel bebas yaitu Penglolaan Anggaran Resiko (X) terhadap variabel terikat Kinerja Organisasi (Y) didapatkan kesimpulan sebagai berikut:

1. Pengujian hipotesis pertama dengan menggunakan uji-t, dapat disimpulkan bahwa secara parsial Pengelolaan Resiko Anggaran $\left(\mathrm{X}_{1}\right)$ berpengaruh signifikan terhadap Kierja Organisasi (Y).

2. Penelitian ini menghasilkan R Square sebesar $50,0 \%$, artinya variabel Kinerja Organisasi (Y) dapat dijelaskan oleh variabel Pengelolaan Resiko Anggaran sebesar 50,0\%. Sedangkan sisanya $50,0 \%$ tidak diteliti dalam model regresi ini. Hal ini menunjukkan bahwa masih ada variabel lain diluar Pengelolaan Resiko Anggaran (X) yang berpengaruh terhadap Kinerja Organisasi (Y).

Saran

1. Untuk memitigasi resiko pada kejanggalan komponen anggaran, dapat dilakukan pengawasan secara periodik baik secara per bulan, tri wulan, per semester atau per tahun tergantug dari penggunaan dana anggarannya yang dianggap akan menimbulkan pertanyaan.

2. Melakukan pengelolaan resiko anggaran tidak hanya dilakukan oleh bagian anggaran saja namun sebaiknya sistem yang dibuat oleh perusahaan dapat secara transparansi dapat dilihat oleh departemen lain yang terkait dengan anggaran untuk memberikan masukan ataupun memberikan peringatan apabila ada penggunaan dana anggaran yang tidak layak.

\section{DAFTAR PUSTAKA}

Chenhall, R. H., \& Langfield-smith, K. I. M. (1999). Innovative accounting systems management, 9(3), 37-46.

CIMA. (2000). CIMA Official Terminology 2005

Edition The Chartered Institute of Management Accountants.

Ghozali, I. (2011). Aplikasi Analisi Multivariate
Dengan Program SPSS 19. Edisi Kelima Semarang: Bandan Penerbitan Universitas Diponegoro.

Hofstede, G. (2011). Dimensionalizing Cultures : The Hofstede Model in Context Dimensionalizing Cultures: The Hofstede Model in Context, 2, 1-26.

Kuncoro, mudrajad. (2010). Metode kuantitatif: teori dan aplikasi untuk bisnis dan ekonomi. In System.

Lanen, W. N., \& Larcker, D. F. (2015). The Association Between Activity-Based Costing and Manufacturing Performance, 40(3), 711726.

Leach, M. A., \& Stemmerjohan, W. W. (2015). Cross Cultural Management: An International Journal Relationship of budget participation conflict and job performance of South Korean managers.

Malhotra, Y. (2004). Measuring Knowledge Assets of a Nation: Knowledge Systems for Development Measuring Knowledge Assets of a Nation:

Malhotra, Y. (2006). Public Management Reform and Organizational Performance: An Empirical Assessment of the U . K . Labour Government' s Public Service Improvement Strategy, 25(2), 371-393. https://doi.org/10.1002/pam

Pavlatos, \& Paggios. (2011). Management accounting practices in the Greek hospitality industry.

https://doi.org/10.1108/02686900910919910

Stevens, D. E., \& Stevens, D. E. (2002). The Effects of Reputation and Ethics on Budgetary Slack The Effects of Reputation and Ethics on Budgetary Slack, (September), 153-171.

Sugiyono, P. D. (2013). Statistik untuk Penelitian. CV. Alvabeta Bandung. https://doi.org/10.1016/S09694765(04)00066-9

Van Helden, G Jan, \& Northcott, D. (2010). EXAMINING THE PRACTICAL RELEVANCE OF PUBLIC SECTOR MANAGEMENT ACCOUNTING RESEARCH, 26(May), 213-240. 